\title{
The Use of Consultant Time in Child Psychiatry- Seven Years On
}

\author{
Dora Black, Consultant Child Psychiatrist, Edgware General Hospital and Michael Black, Consultant Psychiatrist, \\ Bedfordshire Child and Family Psychiatric Service.
}

In 1974 we published a pilot study on the use of consultant time in child psychiatry, based on detailed timesheets kept by a group of child psychiatrists in and near London (1). The group, which is still meeting, decided to see what changes, if any, have occurred over the last seven years in the way we allocate our time. The primary purpose of the group, now, as then, is 'the provision of a forum where members can exchange views and compare experiences relating to the problems encountered while engaging in and often being professionally responsible for administering a child psychiatric service.' A nucleus of about six consultants took part in both studies.

\section{The present study}

Each member of the group was asked to keep a time-sheet detailing all his professional activities from $7 \mathrm{am}$ to midnight over a 14-day period from 23 November to 6 December 1980. The activities were analysed under a number of headings of which the main ones were as in the previous study: (1) direct clinical work, including team discussion and reports and telephone calls; (2) indirect clinical workconsultation with other professionals not in the child guidance/psychiatric team and supervision of the work of other professionals; (3) administration; (4) teaching; and (5) research.

The time spent in private, direct clinical work was gathered separately from NHS work and is not reported here.

\section{Results}

Seventeen out of 23 forms were returned. Fifteen ( 88 per cent) were from whole-time or maximum part-time consultants, compared with 3 ( 25 per cent) in 1974. Two consultants are under $\mathbf{4 0}$ years of age, 8 are between $\mathbf{4 0}$ and 50 , and 7 are over 50. Eight consultants work in clinics with trainees and 9 work without any trainees.

As in 1974, those consultants working in clinics without trainees (solo consultants) work far more than their contracted hours (average 122 per cent, range 85-194 per cent) than those in clinics with trainees (' $T$ ' consultants) (average 100 per cent, range 84-140 per cent), and spend more of their time in direct clinical work (average 60 per cent, range 40-100 per cent for solo consultants compared with an average of 44 per cent, range 22-59 per cent for ' $T$ ' consultants). Solo consultants see about twice as many new families a session $(0.5 \mathrm{c} / \mathrm{w} 0.25)$, but the same number of old families, as ' $T$ ' consultants $(0.7 \mathrm{c} / \mathrm{w} 0.6)$, and this has not changed significantly since 1974 .

Time spent in administration and in indirect clinical work appears to have decreased since the first study (average 27 per cent $c / w 44$ per cent), and time spent in teaching and writing and research has increased, particularly among the solo consultants, who in 1974 were doing virtually no research and spending an average of 8 per cent of their time teaching. They are now averaging 3 per cent on research (range 0-16 per cent) and 12 per cent on teaching (range 0 60 per cent).

About 3.5 hours a week is spent on personal study and 8.5 hours on travelling to and from work. Nine of the $17 \mathrm{con}$ sultants spend more than 7 hours travelling per week.

\section{Discussion}

What are the main differences in the use of consultant time between 1981 and 1974? Certainly, the better staffing of clinics has enabled consultants to reduce their overtime, and this is most marked in those clinics with the largest number of psychiatric trainees. Nevertheless, three-fifths of solo consultants are working more than 110 per cent of their contracted time and in a few cases considerably more (130-194 per cent). Between a third and half of contracted hours is still spent in direct clinical work as in 1974.

Solo consultants, whilst maintaining a heavier case load, appear to be increasing their teaching and research activities- $a$ trend encouraged by the burgeoning of postgraduate medical centres. The tendency in medicine to involve all clinicians in teaching is to be welcomed.

How do child psychiatrists compare with other consultants in the way they use their time? A survey of a 1 in 4 sample of all consultants' pattern of work was undertaken by the Office of Manpower Economics (3) in one week in July 1977. A 51 per cent response was obtained. In that survey child psychiatrists were included with their colleagues in adult psychiatry, mental handicap and psychotherapy, under the heading 'Mental Illness'. Clinical work was defined by exclusion of other activities.

Most clinicians in the OME study spent $80-100$ per cent of their contracted hours on clinical activities. More than a fitth of all consultants worked 145 per cent of their contracted hours; those in paediatrics, geriatrics, general surgery and pathology working the longest hours. More than a third of consultants worked 127 per cent of contracted hours. These figures included legitimate travelling time, unlike ours. If legitimate travelling time were included, over 50 per cent of our group would work more than 127 per cent of contracted hours.

It seems that the consultant child psychiatrists in our study are working at least as long hours as their colleagues 
in other specialties, although they spend less time in direct clinical work and more time in other activities. The concern expressed in our 1974 paper that a misleading impression of our work is given by the current methods of collecting statistics by patient attendances only, is still valid.

Less than half of our group have any junior psychiatric trainees; similarly in Walk's study of 337 child psychiatrists (D. Walk, 1981, personal communication), 59 per cent of consultant child psychiatrists in hospital settings and 34 per cent of those in child guidance clinics had trainees.

\section{Summary and conclusions}

A group of consultant child psychiatrists working in or near London have compared the way they use their time with a similar study done in 1974. The 'teaching' consultants are working less overtime than formerly, but the group as a whole works a similar amount of overtime to colleagues in other specialties. More teaching and research is undertaken by 'non-teaching' consultants than in 1974 .
More child psychiatrists in our study are working whole-time or maximum part-time than in 1974

There has been no change in the proportion of time spent on direct clinical work, and surprisingly no apparent increase in administration, in spite of the proliferation of NHS committees since reorganization. However, it is clear that present methods of collecting statistics by patient attendances only is seriously misrepresenting the volume and scope of the work done by consultant child psychiatrists.

\section{REFERENCES}

Black, D., Black, M. \& Martin, F. (1974) A pilot study on the use of consultant time in child psychiatry. News and Notes, September, pp. 3-5.

DES/DHSS (1974) Circular 3/74, HSC (15)9, on child guidance.

REVIEW BODY ON DOCTORS AND DENTISTS REMUNERATION (1977) Appendix D: Survey of Consultants' Pattern of Work and Responsibilities in the NHS.

\section{Secrets and Gossip: Staff Communication}

\section{Peter Bruggen (Consultant Psychiatrist), Barbara Brillant (Head Teacher) and Suzanne Ide (Nursing Assistant),}

Hill End Adolescent Unit, Hill End Hospital, St Albans, Herts.

We get in a muddle about responsibility and in our communications. Doctors are not the only ones who can discharge patients from hospital-patients can do that themselves (Teeling-Smith, 1979) and the myths about medical responsibility (as if patients are not responsible for themselves) exacerbate feelings of inequality. We are responsible for ourselves and our work; not for our patients or colleagues, much as we may care for them.

We encourage patients and clients to be 'open and direct' in their communications with us, while we avoid eye contact with colleagues in the corridor and in our meetings have a taboo on our own rivalries.

Towards each other's faces we may be friendly, while in their absence we may run down colleagues, administer or prescribe for them (' $\mathrm{X}$ is so disturbed he should be working somewhere else').

First names may be used down hierarchies, but not up. In clinics, the social worker makes the tea; in hospitals, the nurse. In many places doctors still have special treatment over dining rooms, personal telephone calls and parking spaces.

After being bored by what a colleague has said at a case conference or meeting, we pander, reassure or flatter, by lying. Rather than confront colleagues who may not be pulling their weight, we propose spending more to employ extra staff.

Knowledge of the experience of being in charge is withheld from juniors, who are later promoted to face the very problems which they have never seen handled.

People do not feel secure to confront their seniors when administrative decisions regarding them (over rooms, teams, duties, privileges, study leave, promotion) are taken in their absence.

The traditional system is 'vertical' and hierarchical. Formal decisions are made at the tops of hierarchies, to be carried out later by people at the bottom. Memoranda, notices and the 'grapevine' flourish.

Meetings have been introduced to change all this, but unfortunately they have been run with the same conventions, so that people come out of them without having said what they felt, and decisions continue to be made in the corridor. Confrontation occurs only downwards.

\section{Our own method}

In this small institution (with a total staff, including parttimers, of under 30), relationships between the disciplines developed through their coming together as independent groups-multidisciplinary but not interdisciplinary. Secrecy and gossiping about each were frequent.

We decided to have all grades of staff involved in management, with the hope of increasing the status of decisions made and the commitment of staff to them. We also wished to continue to have staff meetings to examine staff conflicts and to understand staff relationships, but wished to prevent 